\title{
Epidemiological determinants and clinical profile of eclampsia: a case control study
}

\author{
Ritam De, Amit Dutta*
}

\begin{abstract}
Department of Obstetrics and Gynecology, Gouri Devi Institute of Medical Sciences and Hospital, Durgapur, West Bengal, India
\end{abstract}

Received: 17 February 2019

Accepted: 11 March 2019

\section{*Correspondence:}

Dr. Amit Dutta,

E-mail: dr.amitdutta49@gmail.com

Copyright: $\odot$ the author(s), publisher and licensee Medip Academy. This is an open-access article distributed under the terms of the Creative Commons Attribution Non-Commercial License, which permits unrestricted non-commercial use, distribution, and reproduction in any medium, provided the original work is properly cited.

\begin{abstract}
Background: The incidence of eclampsia has reduced considerably in the developing countries due to good antenatal care and increased awareness within the population. To determine the magnitude of the problem, to assess trends and to identify risk factors and risk groups, it is worthwhile to periodically review this problem.

Methods: A study using one control for each case of eclampsia was conducted among women who were admitted at Burdwan Medical College and Hospital between July 2014 and June 2015. Cases were women with a confirmed diagnosis of eclampsia. Eclampsia cases were identified by daily monitoring of all new admissions to Eclampsia ward of Burdwan Medical College and hospital. After strict exclusion criteria, a total of 500 eclampsia cases were studied along with same number of controls for identifying the epidemiological determinants.

Results: Maternal age at extremes ( $<20$ and $>30$ years) was identified as a risk factor of eclampsia. Nulliparity has been identified as a risk factor for eclampsia in present study. About $74.6 \%$ mothers were nulliparous. Most of the patients $66.6 \%$ were admitted during the antenatal period i.e. presented with antenatal eclampsia. $62.2 \%$ of them were at between 34-37weeks of gestational age during admission.

Conclusions: Authors observed increased eclampsia risk among women with a prior history of pregnancies complicated by hypertensive disorders. Positive personal histories of hypertensive disorders of pregnancy and family history of hypertensive disorders are well known risk factors of eclampsia. Our findings point to public health and clinical measures that may be taken to potentially attenuate the incidence of eclampsia and mitigate associated maternal-fetal complications resulting from the disorder.
\end{abstract}

Keywords: Eclampsia, Epidemiological determinants, Outcomes, Pregnancy, Risk factors

\section{INTRODUCTION}

The term "eclampsia" is derived from a word meaning "like a flash of lightening". This is the occurrences of generalized convulsions, associated with signs of preeclampsia during pregnancy, labour or within seven days of delivery and not caused by epilepsy or other convulsive disorders. Some authors considered that eclampsia can occur up to ten days following delivery. Eclapmsia remains an important cause of maternal and perinatal morbidity and mortality worldwide. ${ }^{1-3}$ It is estimated that it accounts for more than 50,000 maternal deaths globally. ${ }^{2}$ A large majority of these deaths occur in low-income countries where the quality of maternity care is often inadequate. Although it affects around 1-2\% of the pregnant women population, it contributes approximately $10 \%$ of maternal morbidity in India and other developing countries. In Europe and other developed countries eclampsia complicates about 1 in 2000 deliveries, while in developing countries estimates vary widely from 1 in 100 to 1 in $1700 .{ }^{4}$ The incidence of eclampsia has reduced considerably in the developing 
countries due to good antenatal care and increased awareness within the population. The incidence quoted from the leading centres of India varies from $0.18 \%$ to $4.6 \%$ and approximately $75 \%$ cases occur in primigravidae. Maternal mortality according to various Indian authors is $8-14 \%$ but a low maternal mortality was reported by Menon. ${ }^{5-7}$ In fact worldwide maternal morbidity varies widely at different places with almost identical management indicating that there may be important differences in socio-economic condition of a nation and the quality of obstetric care. To determine the magnitude of the problem, to assess trends and to identify risk factors and risk groups, it is worthwhile to periodically review this problem. In our medical college a significant number of eclampsia patients are referred from health centers. Although it is a tertiary teaching hospital and designed in a semi-urban set up it mainly serves a huge rural part of West Bengal and unfortunately, it is those villages where all the etiological conditions (both medical, economic and social) for eclampsia are prevailing. Only a few thorough research works regarding epidemiological determinants and clinical profile of eclampsia has been conducted previously in this institution. The aim of the present study was to determine the epidemiological determinants and risk factors of eclampsia, to correlate these risk factors with maternal and fetal outcome and to do a critical analysis in order to implement a preventive strategy.

\section{METHODS}

The prospective observational study was conducted in the Department of Obstetrics and Gynaecology, Burdwan Medical College and Hospital, Burdwan, West Bengal over a period of one year (July 2014-June 2015). Study population was consisting of women admitted with eclampsia antenatal, intranatal or postnatal period). A total of 500 cases of eclampsia (approximately) were included.

A predesigned and pre-tested schedule/proforma was used to collect all data.

\section{Inclusion criteria}

All cases of eclampsia-antepartum, intrapartum, postpartum with following diagnostic criteria

- Convulsion/coma occurring at gestational age $>20$ weeks, or within $48 \mathrm{~h}$ of delivery

- Hypertension where BP $140 / 90$ of $\mathrm{Hg}$ or more

- Proteinuria (more than $0.3 \mathrm{gm} / 24 \mathrm{~h}$ or more than +1 in semiquantitative dipstick testing).

In most cases, the patients fulfil all the above criteria. But in several occasions according to the British Eclampsia Study 19958, hypertension and proteinuria may be absent, still the patient have convulsion and receives magnesium sulphate. They will also be included in this study.

\section{Exclusion criteria}

- Patients who have other causes of convulsions such as epilepsy, meningitis, trauma, cerebral malaria etc.

- Diagnosis is doubtful such as convulsion occurs before 20 weeks of gestation or after 48 hours of delivery.

Data was collected with predesigned and pre-tested schedule after taking informed consent. The schedule was containing of details regarding patients' particulars, past obstetric history, past history of hypertension/convulsion, personal history, age of marriage, duration of marriage, marriage-current pregnancy interval, age of menarche, family history, details of current pregnancy, details of antenatal check-up, details of convulsion (whether referred from somewhere or not, timing, number, place, gestational age at that time, convulsion-initial treatment interval etc), details of treatment received, method of induction, mode of delivery, outcome of both mothers (morbidity and mortality) and babies (perinatal morbidity and mortality).

The data was assumed to be normally distributed. Their distribution parameters are expressed in terms of their mean value and standard deviation. The level of variations were compared by student't' test. Nominal data was expressed in percentage $(\%)$ and was compared with chi-square test. Risk factors/causes were expressed in odd's ratio. $\mathrm{P}$ value less than 0.05 ( $\mathrm{p}<0.05)$ was considered statistically significant. The study proposal along with other relevant documents was submitted in the institution review board for review and approval. The study commenced after such approval was obtained in writing from institution Ethics Committee.

\section{RESULTS}

Table 1 shows a strong and significant increased eclampsia among women who were

- $\leq 20$ years age $33.4 \%(\mathrm{OR}=1.2278,95 \%$ CI 0.9391 $1.0653)$.

- $\quad 30-34$ years of age $15.6 \%(\mathrm{OR}=1.1354 ; 95 \% \mathrm{CI}$ 0.8005-1.6105).

- $\quad \geq 35$ years of age $6.4 \%(\mathrm{OR}=1.641 ; 95 \%$ CI 0.9253 2.9105).

Table 1: Distribution according to age.

\begin{tabular}{|l|l|l|}
\hline Age (years) & Control $(\mathbf{n}=500)$ & Eclampsia $(\mathbf{n = 5 0 0 )}$ \\
\hline$<20$ & $145(29 \%)$ & $167(33.4 \%)$ \\
\hline $20-24$ & $125(25 \%)$ & $94(18.8 \%)$ \\
\hline $25-29$ & $140(28 \%)$ & $129(25.8 \%)$ \\
\hline $30-34$ & $70(14 \%)$ & $78(15.6 \%)$ \\
\hline$>35$ & $20(4 \%)$ & $32(6.4 \%)$ \\
\hline
\end{tabular}


Table 2 shows significant increased risk of eclampsia is in nulliparous women $74.6 \% \quad(\mathrm{OR}=1.4862,95 \% \mathrm{CI}$ 1.1302-1.9543).

Table 2: Distribution according to parity.

\begin{tabular}{|l|l|l|}
\hline Parity & Control $(\mathrm{n}=500)$ & Eclampsia $(\mathrm{n}=500)$ \\
\hline Nulliparous & $332(66.4 \%)$ & $373(74.6 \%)$ \\
\hline Multiparous & $168(33.6 \%)$ & $127(25.4 \%)$ \\
\hline
\end{tabular}

Table 3 signified that a potential risk associated with those mothers who have $<7$ (primary) standard educational level $55.6 \% \quad(\mathrm{OR}=1.293$, 95\% CI 1.0083 1.6581) and lowered risk in mothers with higher education.

Table 3: Distribution according to maternal education level.

\begin{tabular}{|l|l|l|}
\hline Maternal & Control $(\mathbf{n = 5 0 0})$ & Eclampsia $(\mathrm{n}=500)$ \\
\hline$>12$ standard & $86(17.2 \%)$ & $58(11.6 \%)$ \\
\hline $7-12$ standard & $168(33.6 \%)$ & $164(32.8 \%)$ \\
\hline$<7$ standard & $246(49.2 \%)$ & $278(55.6 \%)$ \\
\hline
\end{tabular}

Table 4 shows short height mothers $(<150 \mathrm{cms})$ have more propensity for eclampsia $34.6 \%(\mathrm{OR}=1.3064,95 \%$ CI 1.0401-1.7793).

Table 4: Distribution according to height.

\begin{tabular}{|l|l|l|}
\hline Height (CMs) & Control $(\mathrm{n}=500)$ & Eclampsia $(\mathrm{n}=500)$ \\
\hline$<150$ & $140(28 \%)$ & $173(34.6 \%)$ \\
\hline $150-168$ & $270(54 \%)$ & $260(52 \%)$ \\
\hline$>168$ & $90(18 \%)$ & $67(13.4 \%)$ \\
\hline
\end{tabular}

Table 5 found that positive risk of eclampsia in relation to maternal pre-pregnancy BMI.

Women who were underweight $\left(<18.5 \mathrm{~kg} / \mathrm{m}^{2}\right)$ had reduced risk of eclampsia $19 \%(\mathrm{OR}=0.7249,95 \% \mathrm{CI}$ $0.535-0.981$ ) as compared with their counterparts who had a normal pre-pregnancy BMI $\left(18.5-24.9 \mathrm{~kg} / \mathrm{m}^{2}\right)$.

Table 5: Distribution according to BMI (body mass index).

\begin{tabular}{|l|l|l|}
$\begin{array}{l}\text { Body mass } \\
\text { index }\end{array}$ & Control $(\mathbf{n = 5 0 0})$ & Eclampsia $(\mathbf{n = 5 0 0 )}$ \\
\hline$<18.5$ & $120(24 \%)$ & $95(19 \%)$ \\
\hline $18.5-24.9$ & $293(58.6 \%)$ & $294(58.8 \%)$ \\
\hline $25-29.9$ & $54(10.8 \%)$ & $57(11.4 \%)$ \\
\hline$>30$ & $33(6.6 \%)$ & $54(10.8 \%)$ \\
\hline
\end{tabular}

Conversely, obese women $\left(\geq 30 \mathrm{~kg} / \mathrm{m}^{2}\right)$ had increased risk of eclampsia $10.8 \% \quad(\mathrm{OR}=1.7357,95 \%$ CI 1.0987 2.7420).

In Table 6, authors observed that nulliparous women have statistically significant increased risk of eclampsia
74.6\% (OR=1.8185, 95\% CI 1.1392-2.9026). Among multiparous women with prior history of pregnancy associated hypertensive disorders also had a statistically significant increased risk of eclampsia $10.4 \%$ $(\mathrm{OR}=1.0671,95 \% \mathrm{CI}: 1.756-2.636)$.

Table 6: History of hypertensive disorders of pregnancy.

\begin{tabular}{|l|l|l|}
\hline $\begin{array}{l}\text { History of hypertensive } \\
\text { disorders of pregnancy }\end{array}$ & $\begin{array}{l}\text { Control } \\
(\mathbf{n = 5 0 0})\end{array}$ & $\begin{array}{l}\text { Eclampsia } \\
(\mathbf{n = 5 0 0})\end{array}$ \\
\hline $\begin{array}{l}\text { Parous with no prior } \\
\text { history }\end{array}$ & $138(27.6 \%)$ & $75(15 \%)$ \\
\hline Parous with prior history & $30(6 \%)$ & $52(10.4 \%)$ \\
\hline Nulliparous & $332(66.4 \%)$ & $373(74.6 \%)$ \\
\hline
\end{tabular}

Table 7 shows Family history of hypertension was also associated with increased eclampsia risk $19.6 \%$ $(\mathrm{OR}=1.4034,95 \% \mathrm{CI}: 1.007-1.954)$.

Table 7: Family history of hypertension.

\begin{tabular}{|l|l|l|}
$\begin{array}{l}\text { Family history of } \\
\text { hypertension }\end{array}$ & $\begin{array}{l}\text { Control } \\
(\mathbf{n}=500)\end{array}$ & $\begin{array}{l}\text { Eclampsia } \\
(\mathbf{n}=500)\end{array}$ \\
\hline Yes & $74(14.8 \%)$ & $98(19.6 \%)$ \\
\hline No & $426(85.2 \%)$ & $402(80.4 \%)$ \\
\hline
\end{tabular}

Table 8 shows $12.2 \%$ patients had no antenatal visits who had increased risk of eclampsia during pregnancy (OR 1.5152, 95\% CI 1.001-2.292).

Table 8: Distribution according to antenatal care.

\begin{tabular}{|l|l|l|}
\hline Antenatal care & $\begin{array}{l}\text { Control } \\
(\mathrm{n}=500)\end{array}$ & $\begin{array}{l}\text { Eclampsia } \\
(\mathrm{n}=500)\end{array}$ \\
\hline$>3$ antenatal visits & $253(50.6 \%)$ & $201(40.2 \%)$ \\
\hline$<3$ antenatal visits & $205(41 \%)$ & $238(47.6 \%)$ \\
\hline No visit & $42(8.4 \%)$ & $61(12.2 \%)$ \\
\hline
\end{tabular}

Similar increased risk of eclampsia for women who received $<3$ antenatal visits $47.6 \%(\mathrm{OR}=1.3072,95 \% \mathrm{CI}$ 1.017-1.678).

Table 9 shows increased risk of eclampsia in women who have prior history of more 1 abortion $13.2 \%$ (OR 1.3687, 95\% CI 0.9263-2.0223) and also who have more than 2 abortions $4.6 \%$ (OR 1.2912, 95\% CI 0.6879-2.4235).

Table 9: Number of abortions.

\begin{tabular}{|l|l|l|}
$\begin{array}{l}\text { Number of } \\
\text { abortions }\end{array}$ & $\begin{array}{l}\text { Control } \\
(\mathrm{n}=500)\end{array}$ & Eclampsia $(\mathrm{n}=500)$ \\
\hline 0 & $432(86.4 \%)$ & $411(82.2 \%)$ \\
\hline 1 & $50(10 \%)$ & $66(13.2 \%)$ \\
\hline$\geq 2$ & $18(3.6 \%)$ & $23(4.6 \%)$ \\
\hline
\end{tabular}

Table 10 shows most of the eclamptic fits occurred during antenatal period $66.6 \%$ compared to intranatal and postnatal period. Table 11 shows that the blood pressure 
of most to the patients during admission was high. $43.8 \%$ of the patients had systolic blood pressure above $160 \mathrm{~mm}$ of $\mathrm{Hg}$ and $42.8 \%$ patients have diastolic blood pressure between 90-109 $\mathrm{mm}$ of $\mathrm{Hg}$.

Table 10: Types of eclampsia $(n=500)$.

\begin{tabular}{|l|l|l|}
\hline Types & Frequency & Percentage \\
\hline Antepartum & 333 & 66.60 \\
\hline Intrapartum & 90 & 18 \\
\hline Postpartum & 77 & 15.40 \\
\hline
\end{tabular}

Table 12 shows most of the patients $62.2 \%$ admitted with eclampsia had their first convulsion at gestational age between 34-37weeks.

Table 11: Blood Pressure on admission $(n=500)$.

\begin{tabular}{|l|l|l|}
\hline SBP $(\mathrm{mm}$ of Hg) & Frequency & Percentage \\
\hline$\geq 160$ & 219 & 43.80 \\
\hline $140-159$ & 196 & 39.20 \\
\hline$\leq 140$ & 85 & 17.00 \\
\hline DBP (mm of Hg) & Frequency & Percentage \\
\hline$\geq 110$ & 183 & 36.60 \\
\hline $90-109$ & 214 & 42.80 \\
\hline$<90$ & 103 & 20.60 \\
\hline
\end{tabular}

Table 12: Gestational age of $\mathbf{1}^{\text {st }}$ convulsion $(n=500)$.

\begin{tabular}{|l|l|l|}
\hline Gestational age (weeks) & Frequency & Percentage \\
\hline$<34$ & 53 & 10.60 \\
\hline $34-37$ & 311 & 62.20 \\
\hline$>37$ & 136 & 27.20 \\
\hline
\end{tabular}

Table 13 shows that $69.2 \%$ of the eclamptic patients in present study had an average of 2-5 convulsions during their hospital stay.

Table 13: Number of convulsions $(n=500)$.

\begin{tabular}{|l|l|l|}
\hline $\begin{array}{l}\text { Number of } \\
\text { convulsions }\end{array}$ & Frequency & Percentage \\
\hline 1 & 98 & 19.60 \\
\hline $2-5$ & 346 & 69.20 \\
\hline$>5$ & 56 & 11.20 \\
\hline
\end{tabular}

Table 14 shows that there is significantly increased rate of caesarean section $29 \%$ in the eclamptic patients in present study compared to the control group.

Table 14: Mode of delivery.

\begin{tabular}{|l|l|l|}
\hline Mode of Delivery & Frequency & Percentage \\
\hline Vaginal & $396(79.2)$ & $349(69.8)$ \\
\hline LSCS & $93(18.6)$ & $145(29)$ \\
\hline Forceps & $11(2.2)$ & $16(3.2)$ \\
\hline
\end{tabular}

Table 15 illustrates major complication that occurred in present study population was postpartum haemorrhage (16.4\%).

Table 15: Complication of mother

\begin{tabular}{|l|l|l|}
\hline Complication & Frequency & Percentage \\
\hline Nil & 311 & 62.20 \\
\hline Pulmonary Oedema & 58 & 11.60 \\
\hline CVA & 31 & 6.20 \\
\hline PPH & 82 & 16.40 \\
\hline ARF & 9 & 1.80 \\
\hline HELLP & 2 & 0.40 \\
\hline Septicaemia & 4 & 0.80 \\
\hline DIC & 3 & 0.60 \\
\hline
\end{tabular}

Table 16 shows that most babies $90.8 \%$ of the eclamptic mothers were born alive.

Table 16: Outcome of the baby $(n=500)$.

\begin{tabular}{|l|l|l|}
\hline Outcome of baby & Frequency & Percentage \\
\hline Live Birth & 454 & 90.80 \\
\hline Stillborn & 36 & 7.20 \\
\hline IUFD & 10 & 2.00 \\
\hline
\end{tabular}

\section{DISCUSSION}

Eclampsia is still a significant cause of morbidity and mortality for both the mother and fetus. Eclampsia remains a problem that is not preventable and treatable beyond supportive measures and delivery. Unlike preeclampsia, considering the wide gap in the incidence rates, eclampsia is considered a preventable condition. The incidence of eclampsia and the total number of deaths from eclampsia have come down dramatically in developed countries. This has been achieved with improvements in prenatal care and management. However, in developing countries, it still stands as one of the major complications of pregnancy. After obtaining informed consent, enrolled participants were asked to participate in a 30 minute in-person interview in which trained research personnel used a structured questionnaire to elicit information regarding maternal sociodemographic, lifestyle, medical and reproductive characteristics. Participants' prenatal medical records, labor and delivery medical records were also reviewed by trained obstetric research interns and me, using a standardized abstraction form. Information abstracted from medical records included participants pre-pregnancy weight, height, blood pressure, pregnancy complications and condition of the newborn. This study indicates that young and advanced maternal age, pre-pregnancy obesity status, no utilization of prenatal care, hypertensive disorder during pregnancy, family history of hypertension are associated with a significantly increased risk of eclampsia. 


\section{Maternal age}

Socio-demographic and behavioral characteristics of eclampsia cases and normotensive controls are presented in (Table 1). Evidence of a strong and significant increased eclampsia among women who were a) $\leq 20$ years age $33.4 \%(\mathrm{OR}=1.2278,95 \%$ CI $0.9391-1.0653)$; b) $30-34$ years of age $15.6 \%(\mathrm{OR}=1.1354$; $95 \%$ CI 0.8005 $1.6105)$; and $c) \geq 35$ years of age $6.4 \%(\mathrm{OR}=1.641 ; 95 \%$ CI 0.9253-2.9105). Chakraborty et al reported that patients suffering from eclampsia had mean age of 20. Al-Mulhim AA, Abu-Heija et al reported maternal age at extremes $(<20$ and $>40$ years) was identified as a risk factor of eclampsia. ${ }^{9,10}$ Advanced maternal age (>35 years) had also been shown to be associated with increased risk of eclampsia. ${ }^{11}$

\section{Parity}

Nulliparity has been identified as a risk factor for eclampsia in several populations. From Table 2 in present study it is clear that significant increased risk of eclampsia is in nulliparous women $74.6 \%$ ( $\mathrm{OR}=1.4862$, 95\% CI 1.1302-1.9543). Pal et al (1996)12 found 62.5\% of nulliparous women in their study.

\section{Socio-economic status and educational status}

In this study most of the women has come from the low socio-economic status and poor educational status. None of the patient has come from higher socio-economic status. In present study (Table 3 ) signified that a potential risk associated with those mothers who have $<7$ (primary) standard educational level $55.6 \%(\mathrm{OR}=1.293,95 \% \mathrm{CI}$ 1.0083-1.6581) and lowered risk in mothers with higher education. According to Majhi majority of the patients $(82 \%)$ belonged to poor socio-economic status and poor educational status which is largely related with health consciousness and family welfare program among the people. ${ }^{13}$ This indicates that socio-economic status, poor nutrition, illiteracy, lack of awareness and inadequate antenatal care has close relationship with eclampsia.

\section{Maternal height}

Table 4 shows short height mothers $(<150 \mathrm{cms})$ have more propensity for eclampsia $34.6 \%(\mathrm{OR}=1.3064,95 \%$ CI 1.0401-1.7793).

\section{Pre pregnancy body mass index}

Obesity is perhaps the most consistently reported modifiable risk factor of eclampsia.15 In present study Table 5 found positive risk of eclampsia in relation to maternal pre-pregnancy BMI. Women who were underweight $(<18.5 \mathrm{~kg} / \mathrm{m} 2)$ had reduced risk of eclampsia $19 \%(\mathrm{OR}=0.7249,95 \%$ CI $0.535-0.981)$ as compared with their counterparts who had a normal pre-pregnancy BMI (18.5-24.9 kg/m2). Conversely, obese women $(\geq 30$ $\mathrm{kg} / \mathrm{m} 2$ ) had increased risk of eclampsia $10.8 \%$
( $\mathrm{OR}=1.7357,95 \%$ CI 1.0987-2.7420). Although precise biologic mechanisms for associations of eclampsia risk with maternal adiposity are unknown, several possible mechanisms have been proposed. Investigators have speculated that hyperlipidemia, oxidative stress and diffuse endothelial dysfunction are more common among obese versus lean pregnant women. Others have postulated that the association is secondary to alterations in cardiac output. ${ }^{15}$ Although compelling, these hypothesized mechanisms have yet to be evaluated in carefully-designed cohort studies of pregnant women. Mahomed et al. reported that women with eclampsia had a higher BMI $\left(27.6 \pm 4.4 \mathrm{~kg} / \mathrm{m}^{2}\right)$ compared with normotensive women $\left(25.2 \pm 3.8 \mathrm{~kg} / \mathrm{m}^{2}\right) .{ }^{16}$ Mittendorf et al. reported a 2.7-fold increased risk of eclampsia in obese women compared to women with a pre-pregnancy BMI between $18-30 \mathrm{~kg} / \mathrm{m}^{2}{ }^{17}$

Mostello D, et al Reported that recurrence of preeclampsia effects of gestational age at delivery of the first pregnancy, body mass index, paternity and interval between births. ${ }^{6,7,18}$

\section{History of hypertensive disorder during pregnancy and family history of hypertension}

Positive personal histories of hypertensive disorders of pregnancy and family history of hypertensive disorders are well known risk factors of eclampsia. Eclampsia is reported to recur in $13-18 \%$ of subsequent pregnancies. ${ }^{18,19}$ In accordance with previous studies; authors observed increased eclampsia risk among women with a prior history of pregnancies complicated by hypertensive disorders. In present study (Table 6 and Table 7) authors observed that nulliparous women associated hypertensive disorders during pregnancy statistically significant increased risk of eclampsia $74.6 \%$ (OR=1.8185, 95\% CI 1.1392-2.9026). Among multiparous women with prior history of pregnancy associated hypertensive disorders had a statistically significant increased risk of eclampsia $10.4 \%$ (OR=1.0671, 95\%CI: 1.756-13.636). Positive personal histories of hypertensive disorders of pregnancy and family history of hypertensive disorders are well known risk factors of eclampsia. The high recurrence risk of eclampsia, and evidence of familial aggregation of hypertensive disorders supports the concept that a subgroup of women may be predisposed to developing this very dangerous complication of pregnancy. Family history of hypertension was also associated with increased eclampsia risk $19.6 \%(\mathrm{OR}=1.4034,95 \% \mathrm{CI}$ : 1.007-1.954). Odegard et al in their study reported that those with a prior history of eclampsia, compared with women without such a history, had increased risk of the disorder in another pregnancy. ${ }^{20}$

\section{Antenatal care}

In the present study (Table 8), $12.2 \%$ patients had no antenatal visits who had increased risk of eclampsia 
during pregnancy (OR 1.5152, 95\% CI 1.001-2.292). Similar increased risk of eclampsia for women who received $<3$ antenatal visits $47.6 \%(\mathrm{OR}=1.3072,95 \% \mathrm{CI}$ 1.017-1.678). Pal et al found $93.35 \%$ of the cases were un-booked for antenatal care in their study. ${ }^{12}$ According to Majhi, $82.3 \%$ of patients had no antenatal visits. ${ }^{13}$ It has been universally accepted that adequate standard antenatal care has immense value in reducing the incidence of eclampsia by early detection of eclampsia and is prompt management.

\section{Number of abortions}

Table 9 shows increased risk of eclampsia in women who have prior history of more 1 abortion $13.2 \%$ (OR 1.3687 , 95\% CI 0.9263-2.0223) and also who have more than 2 abortions 4.6\% (OR 1.2912, 95\% CI 0.6879-2.4235). Authors observed no significant evidence of associations of eclampsia with maternal addiction (e.g. smoking, alcohol consumptions) and diet.

\section{Types of eclampsia}

In present study (Table 10) shows most of the convulsions occured during antenatal period $66.6 \%$ compared to intranatal and postnatal period.

\section{Blood pressure during admission}

In present study (Table 11) authors found that most of the patients were admitted with high blood pressure. $43.8 \%$ had systolic blood pressure above $160 \mathrm{~mm}$ of $\mathrm{Hg}$ and $42.8 \%$ had diastolic blood pressure between 90-109 mm of $\mathrm{Hg}$. Some patients were also normotensive. High blood pressure was managed with oral nifedipine or injection labetalol according to the individual situations.

\section{Gestational age of first convulsion}

From present study authors found that the $62.2 \%$ of the eclamptic patients were admitted at $34-37$ weeks of gestational age, during which the first convulsion has occured. $27.2 \%$ crossed 37 weeks i.e. term pregnancy during admission. Most antepartum eclampsia occurs in third trimester $(90 \%){ }^{21}$

\section{Number of convulsions}

In present study most of the patients $69.2 \%$ had a total of 2-5 episodes of convulsion during their hospital stay or before being admitted in our hospital. Convulsions were effectively managed with loading and maintenance dose of magnesium sulphate along with additional dose of magnesium sulphate where required.

\section{Mode of delivery}

Though majority of the patients $69.8 \%$ were delivered vaginally there was a significantly increased rate of Caesarean section $29 \%$ among the patients compared with the controlled group $18.6 \%$. Delivery is the only definitive treatment of eclampsia and it must be performed within 12 hours of convulsion. ${ }^{22}$ However, every attempt should be made to stabilize the patient before attempting to deliver. Presence of eclampsia itself is not an indication of caesarean section.

\section{Complications of the mother}

In present study authors found a wide range of complications developed to the mothers during admission, during intrapartum period or after delivery. $16.4 \%$ of the patients developed PPH just after delivery. $11.6 \%$ developed pulmonary oedema cause being unknown. A few patients developed grave complications like HELLP, ARF, DIC and Septicaemia. During present study 26 patients died due to any of these complications. Ten patients died of pulmonary oedema, 8 patients due to CVA, 3 of PPH, 2 in Septicaemia, 2 due to ARF and 1 patient in DIC.

\section{Outcome of the baby}

In present study authors found that most of the babies $90.8 \%$ were born alive owing to prompt management of the mother and prompt delivery. Out of these most of the babies could be salvaged though a number of them were either born pre-term, some of them suffered from birth asphyxia or some were born IUGR. Mothers who delivered pre-term babies were given corticosteroids before delivery for fetal lung maturity.

\section{CONCLUSION}

This study was undertaken as an initial step towards better understanding the epidemiological determinants and clinical profile of eclampsia within a population that is undergoing rapid social, economic, and demographic changes. In conclusion, young and advanced maternal age, obesity, no utilization of prenatal care, history of one or $\geq 2$ abortion, histories of hypertensive disorders of pregnancy and family history of hypertension, short height mothers, nullipara as well as multiparous women from the low socio- economic-educational status without proper or no antenatal care, was identified as epidemiological determinants for eclampsia.

Therefore, the present study provides strong support to find out the epidemiological determinants of eclampsia as well as their clinical profile in a low resource rural set up. To reduce morbidity and mortality resulting from this disease, lifestyle changes and prevention should be the main aim. The early detection of a high-risk factor has the potential to be a predictive tool also for other health disorders with meaningful consequences for the mothers, their offspring and health care systems. Our findings point to public health and clinical measures that may be taken to potentially attenuate the incidence of eclampsia and mitigate associated maternal-fetal complications resulting from the disorder. 
Funding: No funding sources

Conflict of interest: None declared

Ethical approval: The study was approved by the Institutional Ethics Committee

\section{REFERENCES}

1. Duley L, Matar HE, Almerie MQ, Hall DR. Alternative magnesium sulphate regimens for women with pre-eclampsia and eclampsia. Cochrane Database Syst Rev 2010(8):CD007388.

2. Duley L. Maternal mortality associated with hypertensive disorders of pregnancy in Africa, Asia, Latin America and the Caribbean, $\mathrm{Br} \mathrm{J}$ Obstet Gynaecol 1992;99(7):547-53.

3. Barua A, Mundle S, Bracken H, Easterling T, Winikoff B. Facility and personnel factors influencing magnesium sulphate use for eclampsia and pre-eclampsia in 3 Indian hospitals. Int $\mathbf{J}$ Gynecol Obstet. 2011;115(3):231-4.

4. World Health Organisation International Collaborative Study of Hypertensive Disorders of pregnancy.Geographic variation in the incidence of hypertension in pregnancy. Am J Obstet Gynecol 1988; 158(1):80-3.

5. Swain S, Ojha KN, Prakash A, Bhatia BD. Maternal and perinatal mortality due to eclampsia. Indian Pediat. 1993;30(6):771-3.

6. Walker JJ. Modern management of pre-eclampsia and eclampsia in recent advances in Obstetric and Gynaecology, Vol-3, Ed. Dasgupta,New Delhi,Jypee brothers, 1997:P78-97.

7. Menon MKK, Devi PK, Rao KB. Postgraduate Obstetrics and Gynaecology, $4^{\text {th }}$ Edn, Madras (Chennai): 1989: P-52.

8. Chelbi ST, Vaiman D. Genetic and epigenetic factors contribute to the onset of preeclampsia. Molecular Cell Endocrinol. 2008;282(1-2):120-9.

9. Chakraborty B, Dasgupta S. How much Magsulph in eclampsia? - A prospective trial on low dose regime, Indian J Perinatol Reprod Bio 2011;1(5):14-6.

10. Al-Mulhim AA, Abu-Heija A, Al-Jamma F, ElHarith EH. Pre-eclampsia: maternal risk factors and perinatal outcome. Fetal Diagnos Therap. 2003;18(4):275-80.

11. Conde-Agudelo A, Belizán JM. Risk factors for preeclampsia in a large cohort of Latin American and Caribbean women. BJOG: Int J Obstet Gynaecol. 2000;107(1):75-83.
12. Pal B, Niyogi G, Patkar V. A study of eclampsia. J Obstet Gynecol Ind 1996;56:34.

13. Majhi AK. Eclampsia-present scenerio in a referral medical college hospital. J Obstet Gynaecol India. 2001;51:143-7.

14. Stone JL. Lockwood cJ, Berkowitz GS, Alvarez M, Lapinski R, Berkowitz RL. Risk factors for severe preeclampsia. Obstet. Gynecol. 1994;83:357-61.

15. Sanchez SE, Qiu C, Williams MA, Lam N, Sorensen TK. Headaches and migraines are associated with an increased risk of preeclampsia in Peruvian women. Am J Hypertens. 2008;21(3):360-4.

16. Ogbonna C, Woelk GB, Ning Y, Mudzamiri S, Mahomed K, Williams MA. Maternal mid-arm circumference and other anthropometric measures of adiposity in relation to infant birth size among Zimbabwean women. Acta Obstetricia et Gynecologica Scandinavica. 2007 ;86(1):26-32.

17. Mittendorf R, Lain KY, Williams MA, Walker CK. Preeclampsia. A nested, case-control study of risk factors and their interactions. J Reproduct Med. 1996;41(7):491-6.

18. Mostello D, Kallogjeri D, Tungsiripat R, Leet $\mathrm{T}$. Recurrence of preeclampsia: effects of gestational age at delivery of the first pregnancy, body mass index, paternity, and interval between births. Am J Obstet Gynecol. 2008;199(1):55-e1.

19. Ananth CV, Peltier MR, Chavez MR, Kirby RS, Getahun D, Vintzileos AM. Recurrence of ischemic placental disease. Obstetrics Gynecol. 2007;110(1):128-33.

20. Ødegård RA, Vatten LJ, Nilsen ST, Salvesen KÅ, Austgulen R. Risk factors and clinical manifestations of pre-eclampsia. BJOG: Int J Obstet Gynaecol. 2000;107(11):1410-6.

21. Sibai B. Dekker G, Kupferminc M. Pre-eclampsia. Lancet. 2005;365:785-99.

22. Royal College of Obstetricians and Gynecologists. The management of severe pre-eclampsia/eclampsia. Evidence Based Clinical Guideline No 10(A). London: RCOG Press; 2006, Reviewed in 2010.

Cite this article as: De R, Dutta A. Epidemiological determinants and clinical profile of eclampsia: a case control study. Int J Reprod Contracept Obstet Gynecol 2019;8:1531-7. 